J. exp. mar. Biol. Ecol., 1977, Vol. 28, pp. 163-181

C) Elsevier/North-Holland Biomedical Press

\title{
FEEDING AND PARTICLE SELECTION IN THF, ECHIIIRAN WORM BONELLIA VIRIDIS Rolando (ECHIURA: BONELLIIDAE)
}

\author{
V. JACCARINI and P. J. SCHEMBrI
}

The Fort St Lucian Marine Station, The University of Malta, Malta

\begin{abstract}
The feeding behaviour of Bonellia viridis Rolando is described. Small individual particles $(₹ 94+25 \mu \mathrm{m}$ ) are taken onto the proboscis by means of cilia. Individual particles of intermediate size $(150 \pm 40 \mu \mathrm{m})$ are taken up by means of a combination of ciliary and muscular activity. The larger particles $(230 \pm 60$ to $290 \pm 60 \mu \mathrm{m})$ are picked up by muscular action. When presented with large accumulations of particles, the terminal lobes pass them onto the ventral surface of the proboscis by active muscular action.

The ciliary currents on the ventral surface of the proboscis have been mapped. Particles are carried from the terminal lobes of the proboscis to the mouth via the stem gutter, and boluses may be formed at the neck region. Transport along the proboscis may be ciliary for the smaller particles $(<290 \pm 60$ $\mu \mathrm{m})$, ciliary and muscular for the intermediate sizes $(230+60$ to $480+70 \mu \mathrm{m})$ or purely muscular for the largest particles $(550 \pm 140 \mu \mathrm{m})$. Particles may be rejected at various levels along the proboscis, the site of rejection also being dependent on size.

The density of ciliation in the various regions of the proboscis has been estimated and correlated with function. Ventrally (i.e., on the uppper surface) cilia are densest at the fringe region, the terminal lobe gutters, and the lateral margins of the proboscis. The dorsal surface of the proboscis is always extremely sparsely ciliated except for a short distance from the 'leading' edge which has a dense covering of locomotory cilia.

When presented with a monolayer of clean sand grains of different sizes, most animals only pick up particles of $150 \pm 40 \mu \mathrm{m}$ and less. When presented with a choice of clean sand grains or sand enriched with various plant and animal extracts, the terminal lobes actively pick up enriched particles but not, to any appreciable extent, clean sand. The terminal lobes are not attracted to the enriched substratum from a distance. Once on Isochrysis-enriched sand they spend significantly more time on it. With two other plant-enriched substrata (Phaeodactylum and Ulva) they again spend more time on them than on clean sand, but the difference was not statistically significant. The terminal lobes do not feed exclusively on enriched substrata but graze over all the available area.
\end{abstract}

\section{INTRODUCTION}

As far as is known, with the exception of Urechis caupo which is a filter-feeder, all the echiurans are detritus-feeders. The feeding mechanisms of Urechis (Fisher \& MacGinitie, 1928; MacGinitie, 1945), Echiurus (Gislén, 1940; Nyholm \& Bornö, 1969), and Ochetostoma (Chuang, 1962) have been described in some detail. Urechis forms a mucus tube through which it pumps water, filtering out suspended matter, and at intervals the mucus tube containing the trapped particles is ingested. By feeding Urechis with particles of known size, MacGinitie (1945) determined the 'mesh' size of the mucus net spun by this worm. Fisher \& MacGinitie (1928) state that Urechis rejects large particles but did not give any further analysis of this. In Echiurus and Ochetostoma, the proboscis moves over the substratum picking up particles with its 
distal end and transporting them towards the mouth. Gislén (1940) found that the proboscis of Echiurus takes up little material when passing over clean sand but actively picks up large masses of detritus. Large particles are prevented from entering the mouth by the two ventral lips bordering the mouth, the rejected particles being expelled through "the ventral fissure between the lateral margins of the proboscis". According to Chuang (1962) Ochetostoma rejects any particles of a diameter $>1 \mathrm{~mm}$ which reach the mouth region by a mechanism similar to that described for Echiurus. Hughes \& Crisp (1976) have recently described feeding in the echiuran Prashadus pirotansis. The mechanism they give is very similar to that of both Echiurus and Ochetostoma. Prashadus is also, apparently, able to select its food particles. The feeding mechanism of Bonellia has received little attention and there are only general descriptions by Lacaze-Duthiers (1858), Baltzer (1931), and Henke (1972).

Apart from the above work, analysis of food particle selectivity in the Echiura is very meagre. This paper describes the feeding mechanism of the echiuran Bonellia viridis Rolando and analyses experimentally the selectivity of feeding in this animal.

\section{METHODS}

The collection of B. viridis and their maintenance in the laboratory have already been described (Schembri \& Jaccarini, in press). The worms were allowed to acclimatize for a week before being used for observation and experiment. Only healthy animals which fed actively and regularly were used. All the experiments and observations were made under low light intensity (40-100 lux) using red light, and in vibration-free conditions. Sea water used for these experiments had a salinity of $36.5 \%$, a temperature of $20^{\circ} \mathrm{C}$, and was filtered through a Millipore filter $(0.45 \mu \mathrm{m})$ prior to use.

For observation, the worms were placed in shallow dishes of sea water and fine movements of the proboscis were observed under the dissecting microscope. The mechanisms of particle uptake from the substratum were elucidated by observing the behaviour of the proboscis when presented with sand particles of different sizes. Observations were also made on animals feeding on natural detritus both in the laboratory and in the sea. Ciliary currents on the proboscis were traced by observing the movements of carborundum particles of about $45 \mu \mathrm{m}$ diameter placed on the proboscis under the dissecting microscope.

The living cilia were studied by cutting off very small pieces of the proboscis and immediately placing them in a drop of sea water in a cavity slide and observing them under the microscope using phase contrast or Nomarski interference contrast optics.

For scanning electron microscopy, whole animals were narcotized with magnesium chloride and portions of the proboscis cut off and fixed in $4 \%$ glutaraldehyde for $2 \mathrm{~h}$ followed by $1 \%$ osmium tetroxide in isotonic phosphate buffer for $30 \mathrm{~min}$. The specimens were dehydrated by passing through graded alcohols and dried in a critical point apparatus after passing through graded acetone-ethanol mixtures. The speci- 
mens were mounted on aluminium stubs with 'Durofix' cement, cleansed by spraying with 'Freon' gas, coated with gold, and examined in a Cambridge S4 Stereoscan microscope.

The ciliary patterns were mapped by taking photographs at roughly equal distances along various transects along the specimens and counting the number of cilia. Cilia in $1000 \mu \mathrm{m}^{2}$ fields were counted. In the case of low ciliary densities all the cilia in the field were counted; in the case of high ciliary densities a grid was superimposed on the micrographs and random squares counted to give an estimate of the number of cilia in the whole field.

For the experiments on the selection of particles by size, clean beach sand was collected and sun-dried for a week. It was then washed several times with distilled water, and oven-dried. The sand was graded by carefully sieving through nylon bolting silk (Henry Simon Ltd) and sterilized before use. For each trial, sand was lightly sprinkled on to a clean glass slide such that the sand formed a sparse monolayer on the glass. The slide was then positioned in front of the advancing terminal lobes of actively
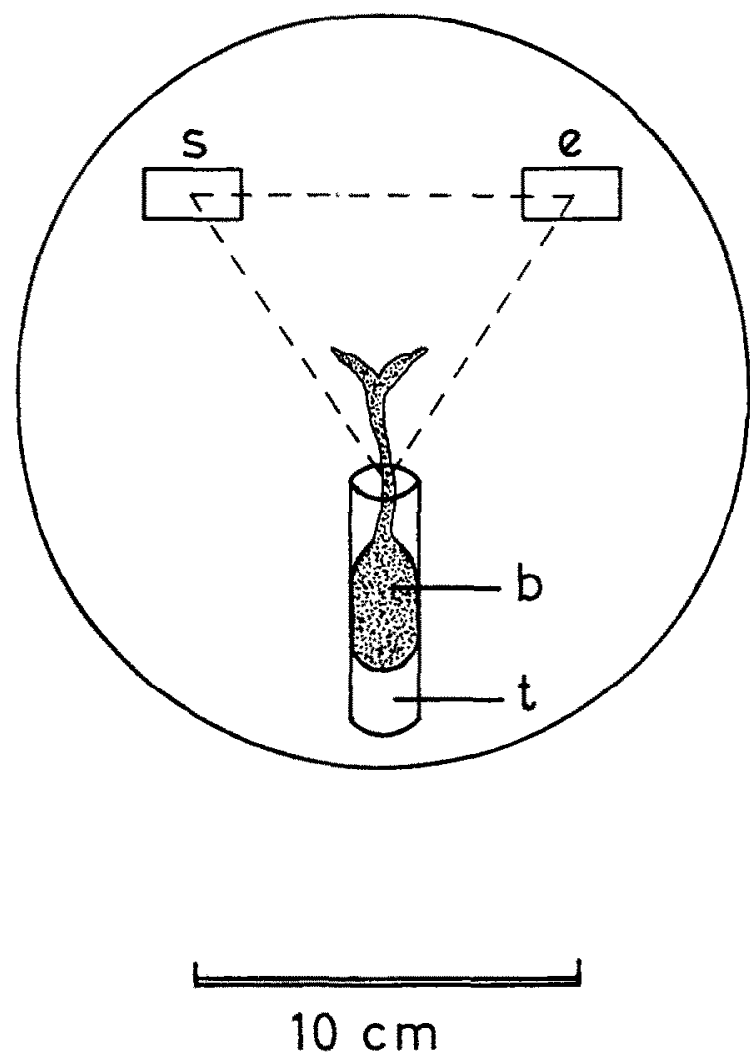

Fig. 1. Design of experiments on the selection of particles by quality: $t$, glass tube containing animal; b, experimental animal; s, slide with clean sand control; $c$, slide with enriched substrate. 
feeding Bonellia whose trunks were in glass tubes in a shallow dish of water. The behaviour of the terminal lobes was observed under the dissecting microscope. After passage of the terminal lobes over the test slide, this was removed and replaced by a new slide for the next trial. Each particle size was tested on the same animal five or more times.

For the experiments on the selection of particles by quality, clean beach sand prepared as for the previous experiments, was sieved to separate the $45-150 \mu \mathrm{m}$ fraction and sterilized. Various enriched substrata were prepared by blending together equal parts by weight of clean sterile sand and 1) cells of the diatom Phaeodactylum tricornutum, 2) cells of the haptophyte Isochrysis galbana separated from the culture medium by centrifugation, 3) homogenized fronds of the multicellular chlorophyte Ulva lactuca, 4) tentacle muscle extract of Octopus vulgaris, and 5) extracts of the soft parts of the mussel Lithophaga lithophaga. Fine $(45 \mu \mathrm{m})$ carborundum powder alone was also tested, clean sterile sand being used as a control. Two scrupulously clean $25 \times 40 \mathrm{~mm}$ glass slides were coated with equal weights of clean sterile sand and enriched sand, respectively, and placed in front of the proboscis-end of a glass tube containing a single Bonellia viridis such that the tube and slides were each at the corners of an equilateral triangle of side $10 \mathrm{~cm}$ (Fig. 1). The proboscis was allowed to wander freely and the period the terminal lobes spent feeding on the control and enriched substratum timed (each period was timed from first contact of the terminal lobes with the glass slide until the last contact). Each trial lasted for $1 \mathrm{~h}$.

\section{RESULTS}

\section{GENERAL OBSERVATIONS ON FEEDING}

$B$. viridis has a cigar-shaped body from which originates a long extensible proboscis anteriorly and dorsally to the mouth. The proboscis consists of a long belt-like stem which bifurcates into two terminal lobes. The external anatomy of Bonellia is shown in Fig. 2. The trunk normally lies with its morphologically ventral surface facing upwards. Correspondingly, the proboscis moves with its morphologically dorsal surface applied to the substratum. Locomotion and other movements of the proboscis have been described elsewhere (Jaccarini \& Schembri, in press).

In nature, individuals live in burrows which have several openings to the exterior in soft calcareous rock. The proboscis is protruded out of the burrow to graze over the surrounding substratum. Since a proboscis in a fully grown animal can often be extended to a length of $1.5 \mathrm{~m}$, it can cover an area of at least $7 \mathrm{~m}^{2}$ without the trunk leaving its burrow. The terminal lobes of the proboscis have been observed to graze on a variety of benthic substrata including shallow pockets of detritus in the rocks, the material at the roots of vegetation, patches of sand between the boulders inhabited by Bonellia, and on the fronds of attached algae.

Bonellia normally feeds in conditions of low light intensity - usually at dusk and dawn and during the night, although the worms may also feed during the day - 
particularly if it is dull and cloudy (see also Henke, 1972). As the terminal lobes move over the substratum, the fringe (Fig. 2), which is of a lighter colour than the rest of the proboscis, picks up particles from the substratum. During this activity it shows a characteristic 'rippling' movement. The ripples are not propagated and

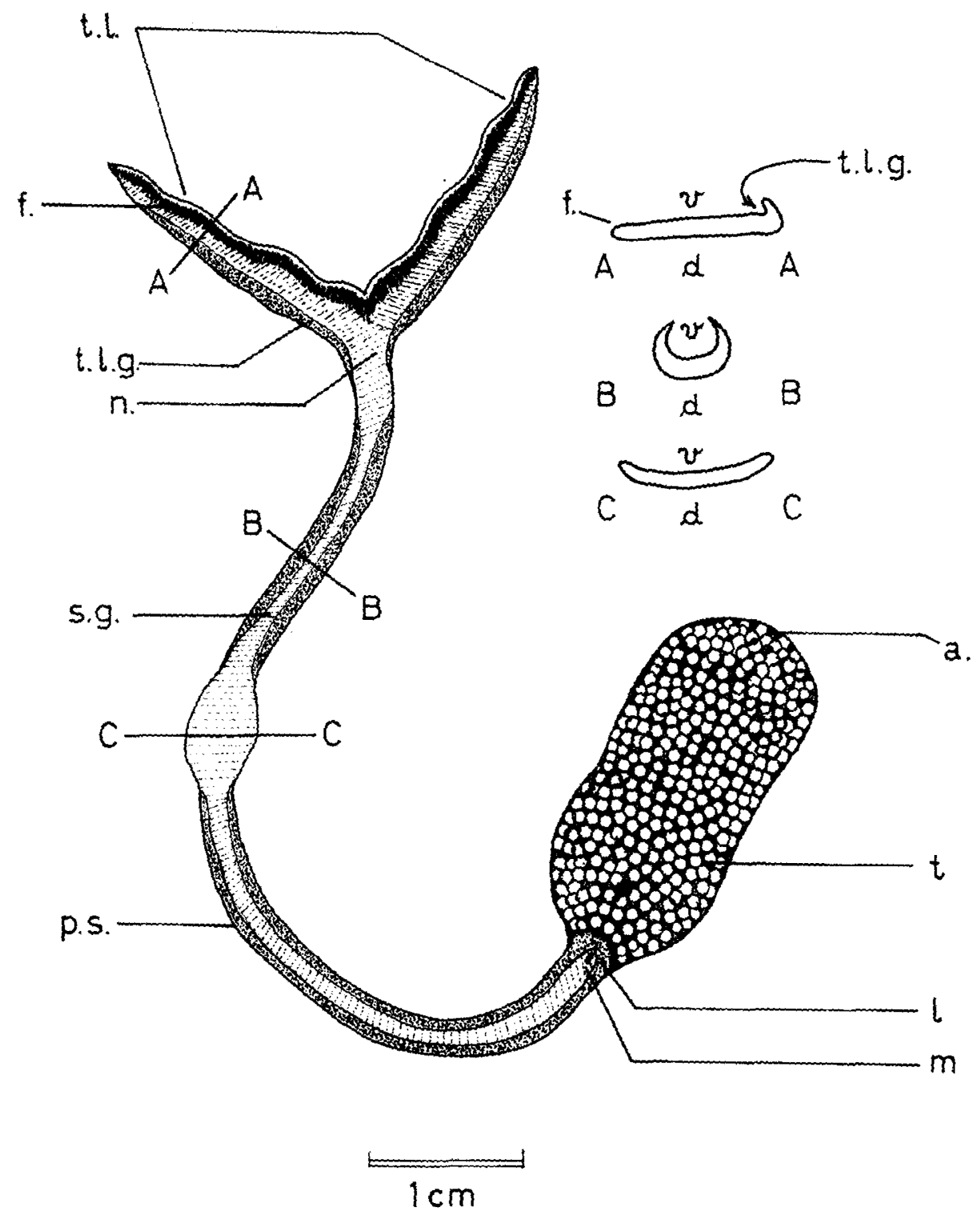

Fig. 2. Diagram illustrating external features of female Bonellia viridis: animal viewed ventrally: insets show schematic transverse sections of the proboscis at jevels marked AA, BB, and CC: a., anus; f., fringe; 1., lip; m., mouth; n., neck; p.s., proboseis stem; s.g., stem gutter; t., trunk; t.l,, terminal lobes; t.l.g., terminal lobe gutter; $v$., ventral surface; $d$., dorsal surface. 
the different stretches of the fringe pucker independently of the rest. Before being picked up by the fringe, particles become coated by mucus which is secreted in large amounts by the terminal lobes.

\section{MECHANISM OF PARTICLE UPTAKE BY THE FRINGE}

Observation on the behaviour of the fringe when presented with particles of different sizes show that there are different mechanisms of particle uptake depending on the size of the particles. The fringe also behaves differently depending on whether it is presented with individual particles or with large accumulations.

Large individual particles $(>360 \pm 60 \mu \mathrm{m})$ of sterile sand are not picked up and
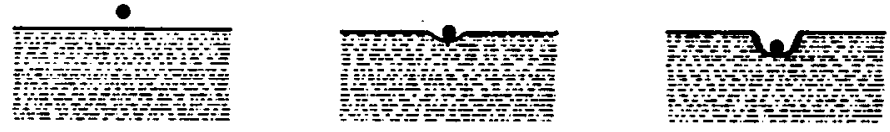

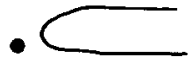

a

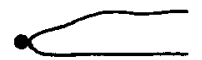

$b$

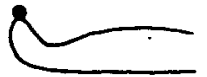

C
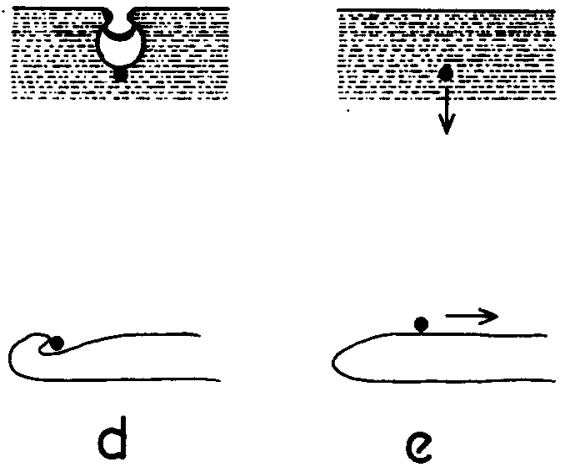

$1 \mathrm{~mm}$

Fig. 3. Uptake of large-sized particle from the substratum by 'pincer' action of the terminal lobe edge: upper diagram in each case, surface view; bottom diagram, side view. 
the terminal lobes glide over them. Particles of intermediate size (150 \pm 40 to $290 \pm 60 \mu \mathrm{m}$ ) are actively picked up by the muscular action of a small length of the fringe. The fringe on either side of a particle glides round it, contracts, thus seizing the particle from the sides rather like a pair of pincers, and bends upwards and backwards in such a way as to transfer the particle onto the upper (ventral) surface of the proboscis (Fig. 3). During this activity, the particles adhere to the proboscis by means of mucus. The numerous powerful cilia present on the fringe beat in this mucus thereby aiding uptake of the particles. The part played by the cilia in the mechanism of particle uptake depends to a greater or lesser extent on the size of the particle. The larger particles are picked up predominantly by the muscular "pincer' mechanism, while the smaller particles are picked up predominantly by ciliary action, the pincer

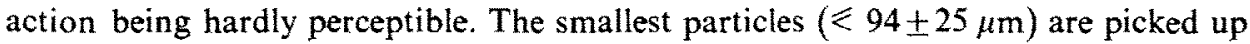
exclusively by the cilia after adhering to the mucus produced by the terminal lobes.

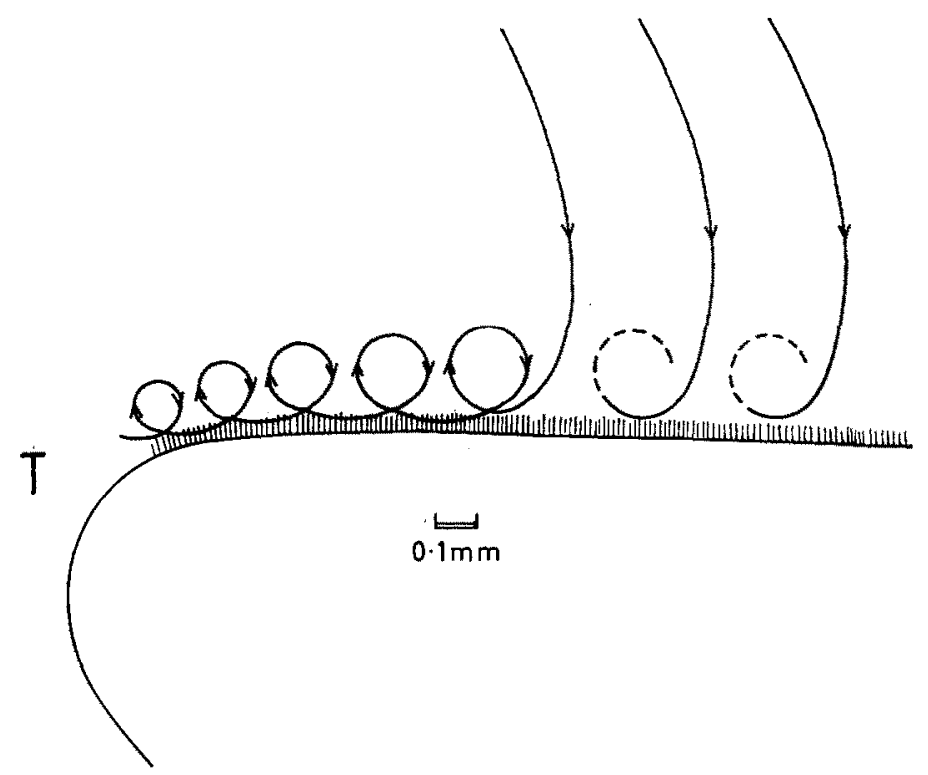

Fig. 4. Diagram showing path of small particles swept towards fringe of terminal lobe by ciliary currents: $T$, tip of terminal lobe.

The cilia at the fringe beat strongly and cause a current of water to flow towards it from some distance away. Very small particles are then transported laterally in a narrowing spiral towards the extreme tip of the terminal lobes (Fig. 4). The fate of these particles could not be followed further due to limitations in the technique used.

On encountering large accumulations of particles the fringe flattens dorso-ventrally and digs into the mass of particles in the manner of a shovel (Fig. 5). The fringe then bends upwards and backwards carrying the large mass of particles it has dis- 
lodged onto the ventral surface of the terminal lobes. The process is repeated as the proboscis advances, masses of particles being dislodged each time.

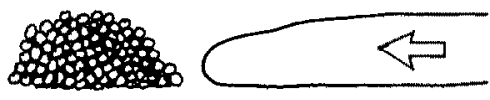

a

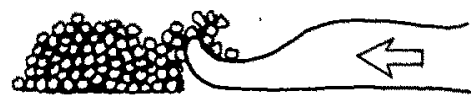

C

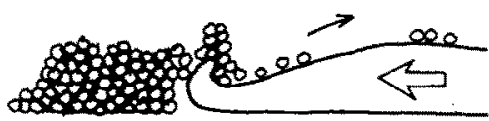

e

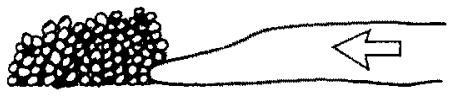

b

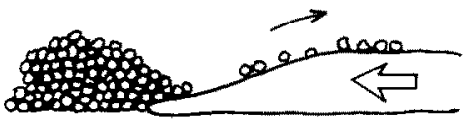

d

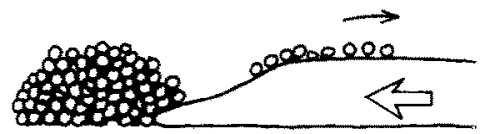

$f$

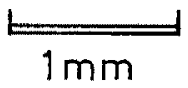

Fig. 5. Mechanism of uptake of heaped particles onto the terminal lobes: sideview: broad arrows show direction of motion of terminal lobes; fine arrows show direction of movement of particles.

\section{FOOD STREAMS ON THE PROBOSCIS}

The ciliary currents on the proboscis were followed using fine carborundum particles. Particles picked up by the fringe are transported backwards to the terminl lobe gutter and are then moved inwards from either side to the neck region (Fig. 6a) where the two streams of particles join. Usually particles are retarded in the neck region, where they accumulate and become concentrated into a dense mass. Contraction of the neck region at the point marked by arrows (Fig. 6a) divides up the particle stream into discreet boluses.

Particles or boluses continue to travel along the stem gutter in a single stream (Fig. 6b). The lateral edges of the stem gutter may either curl upwards forming a 
closed gutter, or else the stem may remain flat. Particles placed experimentally on the edges of the stem gutter remain stationary; when placed further in they move medially and join the main stream. A similar behaviour of introduced particles is observed at the mouth region (Fig. 6c). Powdering the mouth region with fine carborundum powder reveals the presence of a ring of mucus round the base of the proboscis stem. This ring is presumably formed by excess mucus arriving at the mouth region.

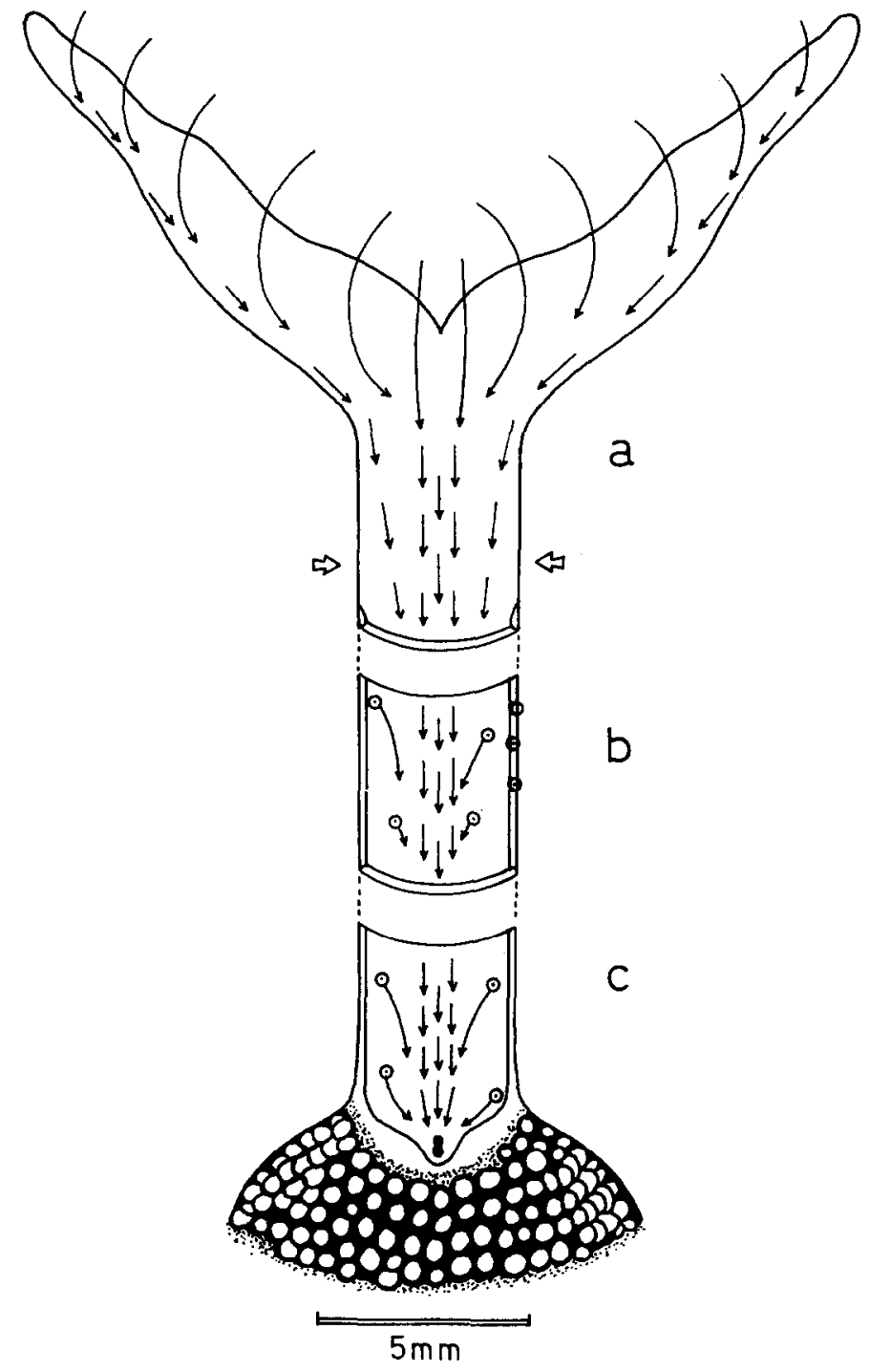

Fig. 6. Ciliary currents (fine arrows) on the proboscis of Bonellia: a, terminal lobes and neck region; $b$, stem gutter; c, mouth region; broad arrows indicate level at which constriction of the neck in bolus formation takes place: $\odot$, positions of particles placed on the proboscis by means of a pipette. 


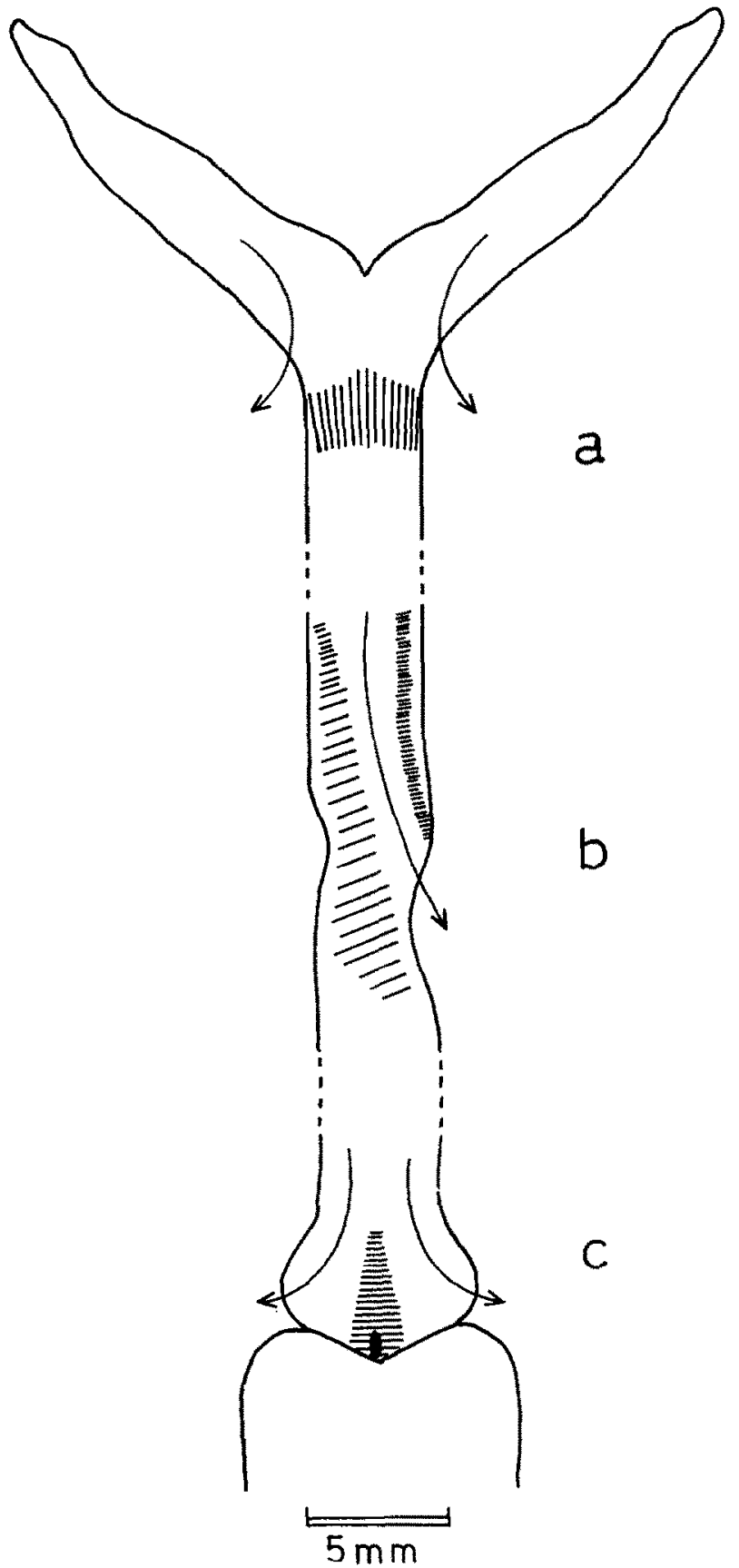

Fig. 7. Rejection path (arrows) of particles on the proboscis: a, neck region; $b$, stem gutter; $c$, mouth region: shaded areas represent regions of contraction. 
At intervals the ring is passed forward towards the terminal lobes and discarded.

While individual particles move along the stem gutter by means of the cilia beating in the mucus, large boluses are transported by peristaltic waves moving from the neck region towards the mouth.

\section{REJECTION OF PARTICLES}

Rejection of particles was studied using sterile sand grains of different sizes. In the neck region of the proboscis, the passage of particles is blocked by means of a bulging of the stem and particles are rejected over the sides (Fig. 7a). Further back along the stem, particles or boluses may be rejected over the sides after transport along an oblique trough formed by muscular contraction of the stem. Particles or boluses may also be rejected at the mouth region. Contraction of that part of the gutter surrounding the mouth obstructs the passage of the boluses into the mouth; the lips of the base of the stem flatten out and material is rejected over the sides. Table I gives an analysis of the mechanism of uptake, the transport mechanism on the proboscis, and the site of rejection of individual particles in relation to size.

\section{TABLE I}

Analysis of particle uptake, transport, and rejection with respect to particle size: activities are referred to as, $\mathrm{M}$, muscular; $\mathrm{M} / \mathrm{C}$, muscular and ciliary; $\mathrm{C}$, ciliary: ${ }^{\mathrm{a}}$ refers to transport both on the terminal lobes and along the stem gutter unless specified otherwise: ${ }^{b}$ in these cases the particles are not picked up and were, therefore, placed experimentally on the terminal lobes.

\begin{tabular}{cccl}
\hline Particle size $(\mu \mathrm{m})$ & Uptake mechanism & Transport mechanism & Rejected at \\
\hline $550 \pm 140$ & None & $\mathbf{M}^{\mathrm{b}}$ & Neck \\
$480 \pm 70$ & None & $\mathrm{M}^{\mathrm{b}}$ & Neck \\
$450 \pm 70$ & None & $\mathrm{M} / \mathrm{C}^{\mathrm{b}}$ & Stem gutter \\
$360 \pm 60$ & None & $\mathrm{M} / \mathrm{C}^{\mathrm{b}}$ & Stem gutter \\
$290 \pm 60$ & $\mathrm{M}$ & $\mathrm{C}$ along terminal lobes & Stem gutter \\
& & $\mathrm{M} / \mathrm{C}$ along stem gutter & \\
$230 \pm 60$ & $\mathrm{M}$ & $\mathrm{C}$ along terminal lobes & Stem gutter or mouth \\
& & $\mathrm{M} / \mathrm{C}$ along stem gutter & \\
$150 \pm 40$ & $\mathrm{C} / \mathrm{C}$ & $\mathrm{C}$ & Stem gutter or mouth \\
$94 \pm 25$ & $\mathrm{C}$ & $\mathrm{C}$ & Stem gutter or mouth \\
$86 \pm 18$ & $\mathrm{C}$ & $\mathrm{C}$ & Mouth \\
$66 \pm 11$ & $\mathrm{C}$ & $\mathrm{C}$ & Mouth \\
$38 \pm 21$ & $\mathrm{C}$ & $\mathrm{C}$ & Mouth \\
\hline
\end{tabular}

\section{DENSITY OF CILIATION}

Since the standard method of analysis using carborundum particles gave no evidence for the existence of discreet tracts of cilia on the proboscis a stereoscan survey of ciliary densities was made. This showed that the cilia are not distributed uniformly 
over the proboscis surface but are arranged in a definite density pattern. The ciliary density (CD) is expressed as number of cilia per $1000 \mu \mathrm{m}^{2}$. The CD is highest at the fringe $(C D>2000)$. As one proceeds backwards across the ventral surface towards the terminal lobe gutter, the density at first falls $(C D=300-400)$ but soon reaches a high sharp maximum ( $C D=700-1100)$ a small distance behind the fringe. From this maximum to the terminal gutter there is a broad region of lower density $(\mathrm{CD}=$ $300-400$ ). The $C D$ of the terminal gutter is about 1000 . Proceeding dorsally from the fringe, the $C D$ falls rapidly to very low values $(C D<100)$. The dorsal surface of the terminal lobes is thus largely devoid of cilia. In the region joining the two terminal lobes with the neck, the density is again high in the fringe and gutter regions, but falls to low levels between them. In the midline transect from the fringe at the junction of the terminal lobes backwards to the beginning of the stem gutter, the CD is again high in the fringe $(\mathrm{CD}=1000-1500)$ and falls off gently as one proceeds backwards $(\mathrm{CD}=300-800)$. A short distance back from the neck region, the ciliary density remains low at the centre $(C D=500)$ but increases as one approaches the lateral edges $(C D=1500)$. Going over the lip onto the dorsal surface of the proboscis stem, the $\mathrm{CD}$ drops very abruptly to very small values $(\mathrm{CD}=20)$. In that part of the gutter just in front of the mouth, ciliary densities of $\approx 500$ were again found medially, rising to about 1000 at the lateral edges of the lips. The body of $B$. viridis is not ciliated.

The cilia as measured from SEM pictures have a length of $\approx 4-5 \mu \mathrm{m}$ in almost all the regions of the proboscis. The cilia are slightly longer $(6 \mu \mathrm{m})$ in the sharp ciliary maximum behind the fringe on the ventral surface of the terminal lobes, and in the terminal lobe gutters. The cilia are also slightly longer than normal in the midline neck region with a length of 6-7 $\mu \mathrm{m}$; again the cilia tend to be longer in the centre of the stem gutter than at the edges.

SEM and light microscopy have shown the presence of peculiar cilia with an expanded tip in certain regions of the proboscis. It is not clear whether these cilia are present in living Bonellia or are a fixation artifact; however, there is evidence that they are not artifacts. This problem is now being investigated.

\section{SELECTION OF PARTICLES BY SIZE}

On encountering the clean sand grains, the terminal lobes either pass over them or pick them up depending on the size of the particles. The results of these experiments are given in Table II. There is no relation between the size of the animal and the size at which particles start being taken up, nor between size of animal and type of mechanism used. In many cases, the proboscis is retracted from the slide after it has sampled the sand for a few seconds. This reaction seems to be a response to contact with particles of no food value since identical sand enriched with various food substances is readily taken up. Few particles are picked up at any time when the particles are devoid of organic matter in contrast with the large amounts picked up when particles 
of the same size are coated with some food substance as described below. Most of the clean sand particles picked up are rejected along the proboscis, and the very few particles swallowed are in the lower end of the size range tested.

TABLE II

Selectivity of particles by size; +, particles taken up; - , particles not taken up.

\begin{tabular}{rccccccc}
\hline \multicolumn{7}{c}{ Particle size $(\mu \mathrm{m})$} \\
Animal & $290 \pm 60$ & $230 \pm 60$ & $150 \pm 40$ & $94 \pm 25$ & $86 \pm 18$ & $66 \pm 11$ & $38 \pm 21$ \\
\hline 1 & - & - & - & + & + & + & + \\
2 & - & - & + & + & + & + & + \\
3 & - & - & - & - & $\cdots$ & + & + \\
4 & - & - & - & + & + & + & + \\
5 & - & + & + & -+ & + & + & + \\
6 & - & - & - & - & + & + & + \\
7 & + & + & + & + & + & + & + \\
8 & - & - & - & - & + & + & + \\
9 & - & - & - & + & + & + & + \\
10 & - & - & - & -- & + & + & + \\
11 & - & - & - & + & + & + & + \\
12 & - & - & - & + & + & + & + \\
13 & - & - & + & + & + & + & + \\
14 & - & + & + & + & + & + & + \\
15 & - & - & - & - & + & + & + \\
\hline
\end{tabular}

As the terminal lobes pass over the monolayer of particles these are covered with mucus and on any following passage of the terminal lobes over them they are never picked up. This may be because they now presumably adhere too firmly to the substratum.

\section{SELECTION OF PARTICLE WITH RESPECT TO QUALITY}

During these experiments it was observed that, in general, the terminal lobes foraged over the entire surface available including the bottom and sides of the containing vessel, the air/water interface, and the internal and external surfaces of the tubes containing the test animal. The trunk often turns round through $180^{\circ}$ in the tube during the course of experiments to come to face the opposite way. In most cases the proboscis is entirely or partly withdrawn at intervals and immediately afterwards starts exploring the substratum in a new direction. Some animals which are actively feeding at the start of the experiment do, however, withdraw their proboscides and refuse to feed further. The results from these animals are not taken into consideration. The results of these experiments are shown in Table III.

The behaviour of the terminal lobes when in contact with an enriched substratum is different from that when in contact with the sand control or carborundum particles or the glass surface. Few or no particles are picked up by the terminal lobes from the sand control or carborundum substratum but when the lobes encounter the enriched 
substratum, they pick up large amounts regardless of whether the enrichment is with plant or animal material. The entire ventral surface of the terminal lobes and stem gutter becomes covered with enriched particles so that the green colour of the proboscis is largely obscured. Most of the food strings and boluses pass into the mouth and are swallowed, only few being rejected in contrast to the almost total rejection of clean sand grains and carborundum particles.

\section{TABLE III}

Means \pm S.D of total time (sec) spent by Bonellia proboscis grazing on the test and control substrata placed on slides during 1 h of observation; control slides were covered with washed and sterilized sand grains: $t$-test for comparison of mean times for test and control substrates: $n$, no. of tests.

\begin{tabular}{lccc}
\hline Substratum & & $\bar{x} \pm$ s.D. & $t$-test \\
\hline Isochrysis & Test & $535 \pm 292$ & $t=2.87 ;$ d.f., $18 ;$ \\
$n=10$ & Control & $235 \pm 154$ & $P=0.01$ \\
Phaeodactylum & Test & $398 \pm 408$ & $t=0.64 ;$ d.f., $16 ;$ \\
$n=9$ & Control & $283.44 \pm 352$ & $P>0.5$ \\
Ulia $n=10$ & Test & $607.2 \pm 489$ & $t=0.43 ;$ d.f., $18 ;$ \\
$n=14$ & $490.2 \pm 712$ & $P>0.5$ \\
Lithophaga & Control & $184.93 \pm 342$ & $t=1.37 ;$ d.f., 26; \\
$n=14$ & Test & $381.43 \pm 413$ & $P<0.2$ \\
Octopus & Control & $199 \pm 246$ & $t=0.80 ;$ d.f., 14; \\
$n=8$ & Test & $295.63 \pm 237$ & $P>0.4$ \\
Carborundum & Control & $399.40 \pm 373$ & $t=0.62 ;$ d.f., $8 ;$ \\
$n=5$ & Test & $582.80 \pm 551$ & $P=0.5$ \\
& Control & & \\
\hline
\end{tabular}

In order to test for the presence of a left- or right-handed bias by the animals, ten animals were each presented with two slides both covered with Phaeodactylumenriched sand. The means in seconds of ten experiments were $350 \pm 207$ for the left slides as against $303 \pm 301$ for the right. There is no significant difference in these means $(t=0.402$; d.f. $18 ; P>0.30)$. Thus a left-right bias is disproved.

In the case of a substratum enriched with the naked flagellate Isochrysis the means of the time in seconds which the animal spent on it was $535 \pm 292$, as opposed to $235 \pm 154$ for the clean sand control. The difference is statistically significant $(t=2.87$; d.f.; $18 ; P=0.01$ ). In the case of the substrata enriched with plant material (Phaeodactylum, Ulva) the means again were higher in the enriched substrata than in the clean controls, but the difference was not statistically significant $(P>0.5)$. In the case of substrata enriched with molluscan tissue (Lithophaga, Octopus) there is an indication that Bonellia reacted negatively, i.e., the proboscis spent less time on the enriched substrata than on the clean control (Lithophaga; $185 \pm 342 \mathrm{sec}$ as opposed to $381 \pm 413$ on the control; Octopus; $199 \pm 246 \mathrm{sec}$ as opposed to $296 \pm 237$ on the control) even though the animal picked up much more of the Lithophaga and Octopus enriched sand than clean sand; however, the difference between the mean times spent on the substrata enriched with molluscan tissue extract and those spent on the unenriched controls were not statistically significant at the $5 \%$ level $(P>0.1)$. 
The heaviest uptake from the enriched substratum is when the terminal lobes encounter it for the first time. During subsequent encounters fewer and fewer particles are, however, taken up - presumably due to the large amounts of mucus secreted by the terminal lobes causing the particles to adhere together. It will be noted that the particles in these experiments were not presented in a monolayer and hence some uptake still took place when the lobes grazed the experimental surfaces again after the first time.

The enriched substrata do not attract the terminal lobes from a distance, i.e., the terminal lobes do not move towards the slide with the enriched substratum in preference to any other region of the containing vessel, nor does the fringe show the characteristic rippling action shown during active 'pick-up' until it makes contact with the enriched substratum. In some cases, the terminal lobes entirely miss the slide containing the enriched substratum even though they pass within a few millimetres of it and so do not encounter it once during the course of the experiment.

\section{Discussion}

\section{COMPARISON WITH OTHER ECHIURANS}

The feeding mechanism of Bonellia differs only in minor detail from that employed by all the other detritus-feeding echiurans so far studied. In all these it is the tip of the proboscis (homologous to the terminal lobes in Bonellia) which is most active in particle uptake; however, in echiurans with a long belt-like proboscis (Ochetostoma, Prashadus) the lateral margins of the proboscis are also able to pick up particles from the substratum (Chuang, 1962; Hughes \& Crisp, 1976). In Prashadus (Hughes \& Crisp, 1976) "the proboscis puckers the edges, lifting particles on to the ciliated [ventral] epithelium". Again, in Ochetostoma the upper (ventral) surface of the distal part of the proboscis is turned downwards (dorsally) to come into contact with the substratum, hence taking up particles by ciliary action (Chuang, 1962). The same author also mentions that the edge of the proboscis puckers and presumably it can take up particles by muscular activity much as has been described above in Bonellia. Gislén (1940) states that particle uptake in Echiurus is mainly ciliary, but that it is also aided by muscular contractions of the fringe. Gislén (1940) and Nyholm \& Bornö (1969) describe the tip of the proboscis of Echiurus as forming a spade which penetrates the substratum. This mechanism is paralleled in Bonellia when the animal feeds on detritus several layers thick. In Echiurus there is a further method of particle uptake (Nyholm \& Bornö, 1969) which is not found in Bonellia. When particles adhere to the mucus on the dorsal surface of the proboscis of Echiurus, they are sometimes transferred to the ventral surface by a rolling up of the proboscis. In Bonellia, when the food-laden proboscis is disturbed, it is withdrawn and coiled up helically in front of the trunk, losing much of its load in the process. In addition to feeding on bottom detritus, Bonellia seems also to have the ability to collect fine particles suspended in the water which are drawn to the sticky ventral surface in the water current produced 
by ciliary beating. The importance of this mechanism in overall feeding of Bonellia is not known, but it may be quite important, since the entire ventral surface of the proboscis of Bonellia is heavily ciliated and secretes large amounts of mucus. Bonellia kept in observation aquaria in the laboratory very often 'graze' along the air-water interface where they could be picking up microscopic particles trapped at the interface. In the sea, fine deposited particles may become resuspended in the water by slight disturbance, and Bonellia may be able to exploit this food source.

Though the feeding mechanism of Bonellia is, then, essentially the same as that of other detritus feeding echiurans so far studied, it is more advanced due to the differentiation and specialization of the various regions of the proboscis. The terminal lobes have taken over exclusively the function of uptake of detritus from the substratum while the stem is mainly concerned with the transport of detritus to the mouth. This, together with the extreme extensibility of the proboscis makes for more efficient feeding over a wider area.

The mechanism of particle uptake and transport along the ventral surface of the proboscis seems to be a function of particle size. In general, very large particles are not taken up onto the proboscis, large particles are taken up and transported by muscular activity, smaller particles by a combination of muscular and ciliary action, and the smallest particles exclusively by ciliary action (Table I). Thus, as size of particle decreases, a muscular mechanism is gradually replaced by a ciliary mechanism.

The site of rejection also appears to be a function of size, at least for individual particles (Table I). The largest particles are rejected anteriorly at the neck of the proboscis stem and the smallest further back near the mouth region. Particles of intermediate size are rejected in intermediate regions, so that as size decreases the site of rejection is further backwards towards the mouth.

No rejection anterior to the mouth region has previously been described for any echiuran. In both Echiurus and Ochetostoma selection of particles and rejection has been described as taking place only at the mouth region and in a way very similar to that described for Bonellia in the present work. In both Ochetostoma and Bonellia, rejected particles are prevented from entering the mouth by a 'bulge' (Chuang, 1962). In Echiurus, it is the "eminence" (which is a permanent feature presumably equivalent to the transient bulge of Ochetostoma and Bonellia) and the ventral lips which prevent unwanted particles from entering the mouth (Gislén, 1940). Thus in all these animals the final phase of rejection is muscular. Also in Prashadus, rejection of particles appears to take place at the mouth region since Hughes \& Crisp (1976), observed that mounds of pseudofaeces collect round the burrow entrance of this worm. These authors do not, however, describe the mechanism of rejection.

The lips are involved in various ways in the feeding of echiurans. In Bonellia they are apposed to form a closed funnel leading to the mouth when the animal is feeding, but flatten out to allow rejected particles or boluses to pass across them and over the edge (Fig. $7 \mathrm{c}$ ). In Ochetostoma the lips are contracted into a funnel when particles are being rejected (Fig. $2 \mathrm{c}$ in Chuang, 1962) but flatten out when particles are being taken 
into the mouth (Fig. 2d in Chuang, 1962) which is opposite to that observed in Bonellia; however, Chuang describes outwardly directed transient ciliary currents on the thickened rim of the most proximal part of the proboscis corresponding to the lip region of Bonellia. Though he does not describe these outward currents as being involved in particle rejection, our observations on Bonellia suggest that this may be so. As stated above, Gislén (1940) found that the lips in Echiurus function to prevent large particles from entering the mouth, these being rejected in a manner similar to that of Ochetostoma, and together with the "eminence' they compact the particles entering the mouth which is what they presumably do in Bonellia. In Urechis the lips play an essential part in manipulating the food-laden mucus tube prior to its ingestion (Fisher \& MacGinitie, 1928).

\section{THE CILIATION}

The ciliation is most dense where the uptake of particles takes place, i.e., in the fringe. This is not unexpected. In those regions where particles are transported in the horizontal plane solely by means of cilia, i.e., in the terminal lobe gutters, the ciliary density is also high, though not as high as in the fringe region. In the regions where particles are transported in a horizontal plane by means of cilia but also with some muscular involvement (the ventral surface of the terminal lobes and the stem gutter) the density is intermediate. In the region where particles are formed into boluses (the neck of the stem) the density is quite high but variable.

It is difficult to account for the high ciliary density present in a band just behind the fringe on the ventral surface of the terminal lobes, i.e., some distance behind the leading edge. In the absence of experimental evidence the following explanation is tentatively put forward. It is possible that this band is involved in the uptake of large particles. As illustrated in Fig. 3 these are first picked up by means of a pincer action of the fringe which then bends upwards and backwards in such a way that the particle is brought above the ventral surface of the terminal lobe (Fig. 3b-d). At the end of this movement the particle presumably does not slide smoothly along the ventral surface of the fringe by means of shear forces acting parallel to the surface, but has to be broken away from its mucous attachment to the fringe by a force acting normally to the area of attachment between the particle and the fringe. It is suggested that this breaking force is exerted by the band of dense cilia just behind the fringe.

Another region of high ciliary density whose function is not obvious is the lateral margin of the stem gutter. This region may function in providing additional force in the transport of boluses when the stem is rolled up lengthwise to form a semi-closed gutter. Another function may be the rejection of particles over the edge of the proboscis stem. The density of cilia on the lips is comparable to that on the lateral margins of the stem gutter and they reject particles presumably in a similar manner to the edge of the proboscis stem.

Gislén (1940) found that in Echiurus the 'eminence' which lies just in front of the mouth had a thick coating of cilia. No such region of high ciliary density in front of 
the mouth could be detected in Bonellia. Chuang (1962) found that the ventral surface of the proboscis of Ochetostoma is covered with cilia of a uniform $11-13 \mu \mathrm{m}$ length (measured on the living animal). Gislén (1940), on the other hand, described longer cilia on the tip (fringe), lateral margins and the 'eminence' of the proboscis of Echiurus. In Bonellia the length of the cilia shows some regional differentiation, but the differences are small and the length ranges between 4-7 $\mu \mathrm{m}$ as measured on scanning electron micrographs.

\section{SELECTION BY SIZE}

Bonellia selects particles by size at the terminal lobes, at least when the particles have no food value and are presented as a sparse monolayer (Table II). All the animals tested picked up particles $<66 \mu \mathrm{m}, 93 \%$ of the animals $<86 \mu \mathrm{m}, 67 \%<94 \mu \mathrm{m}$, and $33 \%<150 \mu \mathrm{m}$. None of the animals picked up particles $>290 \mu \mathrm{m}$. The fact that Bonellia selects particles mostly $<150 \mu \mathrm{m}$ is very probably not unrelated to the fact that it is at around $150 \mu \mathrm{m}$ that the muscular method of uptake is used. Particles $<150 \mu \mathrm{m}$ are picked up exclusively by ciliary action.

The particles of sand used in the experiments on selection by size all had approximately the same density, and so the largest particles were also the heaviest. Selectivity with respect to weight was not tested but it is clear from observations on worms feeding on natural detritus that the animals also select particles by weight. Heavy particles are not picked up, irrespective of size, while within wide limits light particles are picked up, e.g., Bonellia are frequently observed to pick up and ingest large plant fibres ( $5 \mathrm{~mm}$ in length) from the substratum, while smaller, but obviously heavier particles $(0.5 \mathrm{~mm}$, Table II) are not picked up.

The ability of Bonellia to select particles by size is of clear functional significance, particularly since the organic content of finely divided detritus is higher than that of coarser detritus (Newell, 1970, p. 249).

\section{SLLECTION BY QUALITY}

The experiments with enriched substrata provide evidence that Bonellia shows sclectivity with respect to particle quality. It spends more time on plant-enriched substrata than on the clean control substrata and less time on substrata enriched with molluscan tissue as compared with that on unenriched substrata (only in the case of sand enriched with Isochrysis was the difference statistically significant at the $1 \%$ level). Moreover, the interpretation of this selectivity must take into account the fact that the proboscis picks up incomparably many more particles of the enriched substratum than of the clean sterile control, irrespective of whether the enrichment was with plant or animal material. Thus there seem to be two kinds of receptors. The animal must have epidermal sensory receptors situated in the leading fringe region which recognize organic material. Input from the receptors presumably leads to greater activity in the particle uptake systems (ciliary and muscular). Other receptors dis- 
criminate between different kinds of organic material and input from these receptors leads to greater activity in the dorsal locomotory cilia. These receptors are possibly located further back than the former. Receptors in the fringe have been seen in sections (unpubl. results). Evidence for receptors in the stem is also provided by the way particles are taken up anteriorly and rejected at various points along the stem as already described.

\section{ACKNOWLEDGEMENTS}

This work involved the use of equipment obtained by a grant from the Development Fund of Barclays Bank International towards the setting up of the Fort St Lucian Marine Station.

One of us (P.J.S.) is grateful to the trustees of the Marquis Scicluna Trust Fund for the award of a junior travelling fellowship to Bristol University and to Professor G. M. Hughes and Dr A. Dorey of that University for their helpful advice. Thanks are also due to Mr J. Clements of Bristol University and Mr J. B. Kirkham of Queen Mary College for their help with the Stereoscan work. We wish to thank also Dr A. Leone-Ganado for advice on statistical analysis and Professor Norman Millott for his constructive comments on the manuscript.

Finally we wish to thank Mr S. Sciberras and Mr A. Fenech for their help in obtaining the animals.

\section{REFERENCES}

Baltzer, F, 1931. Echiurida. In, Handbuch der Zoologie, Bd 2, edited by W. Kükenthal \& T. Krumbach, De Gruyter, Berlin \& Leipzig, S. 62-168.

Chuang, S. H., 1962. Feeding mechanism of the echiuroid, Ochetostoma erythrogrammon Leuckart \& Rueppell, 1828. Biol. Bull. mar. biol. Lab., Woods Hole, Vol. 123, pp. 80-85.

Fisher, W. K. \& G. E. MACGinitie, 1928. The natural history of an echiuroid worm. Ann. Mag. Nat. Hist. Ser. 10, Vol. 1, pp. 204-213.

Gisı.́́n, T., 1940. Investigation on the ecology of Echiurus. Lunds. Univ. Arsskr. N.F., Vol. 36, pp. 135.

Henke, J., 197:. Ergänzende Bemerkungen zur Makrofauna der spanischen Südküste. Zool. Anz., Bd 189, S. 348-351.

Hughes, R. N. \& D. J. CRise, 1976. A further description of the echiuran Prashadus pirotansis. J. Zool., Lond., Vol. 180, pp. 233-242.

JACCARIN1, V. \& P. J. SCHEMBRI, in press. Locomotory and other movements of the proboscis of Bonellia viridis (Echiura, Bonelliidae). J. Zool., Lond.

LACAZE-Duthiers, H. DE, 1858. Recherches sur la Bonellie (Bonellia viridis). Annls Sci. nat. (Zool.), Ser. 4, T. 10, pn. 49-110.

MacGinitie, G. E., 1945. The size of the mesh openings in mucous feeding nets of marine animals. Biol. Bull. mar. biol. Lab., Woods Hole, Vol. 88, pp. 107-111.

Newell, R. C., 1970. Biology of intertidal animals. Paul Elek (Scientific Books) Ltd, London, 555 pp.

Nyholm, K.-G. \& C. Bornö, 1969. The food uptake of Echiurus echiurus Pallas. Zool. Bidr. Upps Vol. 38, pp. 249-254.

Schembri, P. J. \& V. JacCarini, in press. Locomotory and other movements of the trunk of Bonellia viridis (Echiurd, Bonellidae). J. Zool., Lond. 